\title{
Analisis kebutuhan pengembangan edukit ipa terintegrasi mobile application pada tema getaran dan gelombang untuk melatih keterampilan problem solving siswa
}

\author{
Dzakiyya Alya Maharani, Erni Yulianti, Sugiyanto \\ Universitas Negeri Malang, Jl. Semarang No. 5 Malang, Jawa Timur, Indonesia \\ *Penulis korespondensi, Surel: erni.yulianti.fmipa@um.ac.id
}

Paper received: 01-05-2021; revised: 15-05-2021; accepted: 31-05-2021

\begin{abstract}
Abstrak
Tujuan dari analisis kebutuhan ini adalah memberikan kajian terkait media pembelajaran yang dapat melatih keterampilan pemecahan masalah siswa, yaitu dengan menggunakan edukit IPA yang terintegrasi Mobile Application pada tema getaran dan gelombang. Tuntutan pembelajaran yang terdapat dalam kurikulum 2013 adalah memindahkan fokus pendidikan dari menghafal fakta dan pengetahuan teoritis kepada siswa untuk dapat mencapai kompetensi menjadi kegiatan penemuan konsep oleh siswa. Proses pembelajaran terdiri dari lima pengalaman belajar utama yaitu mengamati, bertanya, bereksperimen, mengasosiasi, dan berkomunikasi. Praktikum di laboratorium yang dilaksanakan dengan efektif, dapat menjadi sumber belajar siswa untuk memahami sains, selain itu kegiatan laboratorium juga merupakan proses dari pemecahan masalah. Kegiatan laboratorium di mana siswa dilibatkan langsung dalam pemecahan masalah dapat meningkatkan kreatifitas berpikirnya. Alat praktikum yang tersedia di laboratorium cukup besar sehingga kurang efisien dalam penggunaannya, maka inovasi yang diberikan adalah menggunakan alternatif lain yaitu Edukit. Edukit atau microscale adalah bentuk sederhana dari alat praktikum yang biasanya tersedia di laboratorium. Edukit ini nantinya akan dilengkapi dengan buku panduan yang menjelaskan prosedur percobaan, kemudian di dalam buku panduan disertasi barcode yang akan terhubung dengan mobile application. Metode yang digunakan dalam penelitian ini adalah studi literature dan studi kasus terhadap pihak-pihak yang bersangkutan.
\end{abstract}

Kata kunci: Edukit IPA, keterampilan Problem Solving, Getaran dan Gelombang

\section{Pendahuluan}

Perkembangan teknologi memberikan banyak dampak positif dalam berbagai bidang, salah satunya adalah di bidang pendidikan. Teknologi menuntut guru sebagai pemegang pemeran utama dalam dunia pendidikan untuk melakukan perbaikan dalam mengajar. Kurikulum disusun sesuai dengan perkembangan teknologi, di mana siswa dilibatkan secara aktif melalui kegiatan-kegiatan saintifik. Kegiatan saintifik yaitu mulai dari mengamati hingga tahap tertinggi yaitu mencipta, hal ini dimaksudkan agar siswa memiliki keterampilan proses sains (Rusdianawati \& Sukarmin, 2017). Mata pelajaran integrative science saat ini diterapkan pada pembelajaran IPA, artinya pembelajaran IPA ini memadukan tiga ranah yaitu ranah sikap, ranah pengetahuan, dan ranah keterampilan. IPA memiliki hubungan yang erat dengan lingkungan, teknologi dan bidang lainnya (Prasetyowati, 2014). Pembelajaran IPA sangatlah luas, maka dalam praktiknya, siswa tidak hanya mendapatkan materi untuk dihafal namun pembelajaran juga dikaitkan dengan ranah sikap dan keterampilan. Sikap ilmiah dapat berupa teliti dalam mengambil data, percaya diri, memiliki keyakinan akan data yang mereka miliki, dan lain sebagainya.

IPA memiliki karakteristik sebagai proses penemuan kebenaran ilmiah, ini berarti siswa dilatih untuk melakukan suatu proses penemuan konsep. Siswa yang dilatih untuk 
melalui proses ini akan mendapatkan pembelajaran yang lebih bermakna, karena mereka memulai penemuan dengan mengamati fenomena IPA di sekitarnya, kemudian melakukan penyelidikan, dan menyimpulkan hasil penyelidikan. Kegiatan proses penemuan ini adalah melakukan praktikum yang dilakukan di laboratorium. Menurut (Emda, 2017) laboratorium dapat menjadi sumber belajar dalam kegiatan memecahkan masalah. Kegiatan di laboratorium dapat memfasilitasi siswa untuk memahami sains, selain itu kegiatan laboratorium juga merupakan proses dari pemecahan masalah (Panjaitan, Sujana, \& Jayadinata, 2019).

Nyatanya pembelajaran IPA belum sepenuhnya dilaksanakan dengan berpusat pada siswa melainkan masih banyak yang berpusat pada guru. Pembelajaran teacher centered berarti guru lebih aktif dalam menjelaskan materi sedangkan murid sebatas menyimak penjelasan guru. Kurangnya kreativitas pada guru ini karena adanya keterbatasan media pembelajaran yang dapat digunakan (Almeida, Martins, Sá, Pires, \& Tremoço, 2019). Media pembelajaran saat ini memberikan peran penting dan contoh inovatif yang searah dengan berkembangnya teknologi dalam pendidikan dan teknologi dalam pembelajaran (Nurseto, 2012). Media merupakan tempat atau sarana untuk menyampaikan suatu informasi dari suatu narasumber kepada sasaran tertentu (Mahnun, 2012).

Menurut Nurrita (2018), media pembelajaran merupakan unsur yang penting dalam proses pembelajaran. Dengan adanya media pembelajaran maka siswa akan lebih aktif dalam belajar. Sebelumnya telah dipaparkan apabila kegiatan praktikum dapat meningkatkan keaktifan siswa baik dalam hal kegiatan maupun pola pikirnya. Alat dan bahan yang digunakan ketika praktikum juga termasuk dalam media pembelajaran.

Kegiatan praktikum masih kurang maksimal di lingkungan sekolah. Salah satu dari beberapa kendala yang mengakibatkan kegiatan praktikum kurang dimaksimalkan adalah karena kurangnya jumlah dari set praktikum yang nantinya digunakan oleh siswa. kesempatan siswa dalam melakukan praktikum menjadi sedikit, karena mereka harus berbagi satu alat praktikum dengan banyak siswa lainnya. Kondisi ini akan membatasi kerja aktif dari siswa, karena yang melakukan praktikum hanya dua atau tiga siswa sedangkan yang lainnya cenderung menjadi pengamat yang pasif (Abdullah, Mohamed, \& Ismail, 2009). Ukuran alat praktikum di laboratorium juga terlalu besar sehingga akan sulit untuk dipindahkan apabila ruangan tidak memadai dan ingin melakukan praktikum di luar kelas. Kit praktikum atau microscale adalah bentuk lebih kecil dari alat praktikum yang biasanya tersedia di laboratorium. Kelebihan lain dari kit praktikum yaitu mampu memvisualisasi serta mendeskripsikan proses yang rumit menjadi lebih mudah dipahami (Harahap, 2019).

\section{Metode}

Metode yang digunakan dalam penelitian yakni metode deskripsi kualitatif. Penelitian dengan metode ini dilakukan dengan mengkaji fakta di sekolah-sekolah terkait kekurangan atau kendala yang dialami selama pembelajaran berlangsung. Berdasarkan beberapa hasil kajian fakta tersebut, ditemukan suatu variabel yang saling berhubungan, sehingga dihasilkan sebuah solusi. Metode ini sesuai dengan tahapan penelitian yang dilakukan. Permasalahan yang terjadi di sekolah adalah kurang efektifnya kegiatan praktikum karena alat dan tempat yang kurang memadai, sehingga alat percobaan diganti dengan menggunakan kit agar lebih efisien. Untuk mendukung kit sehingga siswa dapat memahami langkah-langkah percobaan, kit dilengkapi 
dengan buku panduan dan terintegrasi dengan mobile application. Media pembelajaran dalam bentuk kit ini dapat meningkatkan keterampilan problem solving siswa.

\section{Hasil dan Pembahasan}

Pembelajaran abad ke 21 adalah pembelajaran yang menggabungkan beberapa aspek, yaitu keterampilan literasi, pengetahuan, sikap ilmiah, dan penguasaan teknologi. Diharapkan kemampuan siswa dapat meningkat ketika menghadapi suatu permasalahan, di mana siswa akan mengidentifikasi permasalahan tersebut dahulu, kemudian merumuskan hipotesis, kemudian melakukan evaluasi kegiatan, dan akhirnya mereka dapat menemukan berbagai alternatif prediksi sebagai solusi (Helfira, Ratnawulan, \& Gusnedi, 2019).

Kegiatan penemuan konsep ini dapat dilakukan melalui penyelidikan di laboratorium. Kegiatan penyelidikan ini biasa disebut dengan praktikum. Melalui kegiatan praktikum, siswa dapat berinteraksi langsung dengan objek alam (Forcino, 2013). Kegiatan laboratorium yang dimaksudkan adalah kegiatan percobaan yang melibatkan siswa dalam kelompok kecil, tidak termasuk kegiatan percobaan yang melibatkan siswa dalam kelompok besar atau kunjungan lapangan. Ketika melakukan praktikum, siswa melalui dua tahapan, yaitu pre-lab yaitu kegiatan persiapan sebelum praktikum dan tahap post-lab yaitu kegiatan siswa menganalisis dan mendiskusikan data yang diperoleh (Leite \& Dourado, 2013).

Praktikum yang dilakukan dengan efektif dan tepat dapat meningkatkan keterampilan problem solving siswa. Pada kegiatan laboratorium, permasalahan diberikan kepada siswa yang sebelumnya belum pernah mengetahui solusinya, atau situasi di mana permasalahan tersebut telah ada namun belum teridentifikasi oleh siswa (Hofstein \& Lunetta, 2015). Pemecahan masalah (problem solving) dapat didefinisikan sebagai proses yang digunakan untuk mendapatkan jawaban yang paling tepat dari suatu hal yang belum diketahui sebelumnya, atau penentuan keputusan atas beberapa kendala (Al-khatib, 2012). Terdapat empat indicator problem solving dalam pemecahan suatu masalah yaitu: (1) pemahaman masalah, (2) melakukan perencanaan solusi terhadap masalah, (3) menyelesaikan masalah sesuai yang telah direncanakan, dan (4) melakukan review terhadap hasil akhirnya (looking back) (Polya, 1945).

Kegiatan praktikum dapat meningkatkan keterampilan problem solving siswa, hal ini didasari dari hasil penelitian yang pernah dilakukan. Penelitian yang dilakukan oleh Usrotin, dkk. (2013), setelah dilakukan praktikum, hasil rata-rata nilai postes keterampilan problem solving siswa kelas eksperimen mengalami peningkatan jika dibandingkan dengan nilai pretes yaitu sebesar 18,67\% sedangkan kelas kontrol mengalami peningkatan 4\%. Peningkatan nilai keterampilan problem solving yang tinggi juga dapat dilihat dari hasil penelitian Sutarno, dkk. (2017). Kelas eksperimen memperoleh peningkatan rata-rata nilai postes lebih tinggi $28 \%$ dibandingkan kelas kontrol.

Karakteristik konsep IPA yang abstrak sesuai dengan pembelajaran laboratorium. Konsep getaran dan gelombang termasuk konsep abstrak sehingga siswa sulit untuk memahami (Jumadin, dkk., 2017). Observasi yang dilakukan oleh Meliarti, dkk. (2015) pada guru di SMP 14 Negeri Pontianak, kesulitan dialami siswa ketika belajar materi gelombang yaitu 1) menjelaskan konsep gelombang, 2) sulit dalam membedakan gelombang transversal dan longitudinal, dan 3) tidak mampu menghitung frekuensi dan cepat rambat gelombang. 
Oleh karena itu, untuk memudahkan siswa dalam memahami materi getaran dan gelombang diperlukan kegiatan praktikum.

Kegiatan pembelajaran di laboratorium belum dapat dimanfaatkan secara optimal oleh guru dalam pembelajaran. Kendala yang dialami guru ketika akan melakukan kegiatan praktikum yaitu sekolah tidak memiliki fasilitas laboratorium yang baik, minimnya ketersediaan peralatan praktikum, dan kegiatan praktikum banyak menghabiskan waktu (Putri \& Risdianto, 2014). Kondisi ini akan membatasi kerja siswa (Abdullah et al., 2009). Agar memudahkan siswa dan guru dalam melakukan praktikum, maka dibutuhkan suatu media pembelajaran.

Berdasarkan hasil pengamatan lapangan dan wawancara di SMP kabupaten Blitar yaitu SMPN 01 Sutojayan dan di SMPN 23 Malang terkait kendala yang sering guru IPA hadapi ketika akan melakukan praktikum adalah, 1) ruang laboratorium digunakan untuk ruang kelas sehingga tidak dapat digunakan dengan optimal, 2) apabila siswa akan praktikum, alat dan bahan dipindahkan ke kelas. Hal ini juga mengakibatkan jenis praktikum yang dilakukan siswa terbatas, 3) kit praktikum yang tersedia di laboratorium tidak ditata untuk satu jenis percobaan saja sehingga sulit untuk memilah, 4) ukuran kit praktikum terlalu besar sehingga sulit apabila ingin dipindah-pindahkan, 5) jumlah alat dan bahan praktikum terbatas, sehingga ketika praktikum, hanya dengan demo guru dan siswa mengamati saja. Dengan beberapa kendala ini, produk edukit IPA terintegrasi mobile application tepat guna.

\section{Simpulan}

\subsection{Kesimpulan}

Berdasarkan uraian yang telah dijelaskan diatas maka dapat disimpulkan bahwa dibutuhkan Edukit IPA Terintegrasi Mobile Application pada Tema Getaran dan Gelombang untuk Melatih Keterampilan Problem Solving

\subsection{Saran}

Perlu dilakukan uji coba dengan responden lebih luas untuk melihat keefektifan edukit IPA tema getaran dan gelombang ini.

\section{Daftar Rujukan}

Abdullah, M., Mohamed, N., \& Ismail, Z. H. (2009). The effect of an individualized laboratory approach through microscale chemistry experimentation on students ' understanding of chemistry concepts , motivation and attitudes. 53-61. https://doi.org/10.1039/b901461f

Al-khatib, B. A. (2012). The Effect of Using Brainstorming Strategy in Developing Creative Problem Solving Skills among Female Students in Princess Alia University College Department of Psychology and Special Education. American International Journal of Contemporary Research, 2(10), 29-38.

Almeida, M. J. de, Martins, D. R., Sá, M. V, Pires, A. J., \& Tremoço, J. J. (2019). Student Centered Teaching Activities in Secondary Schools and Misconceptions Evolution : Basic Mechanics. Journal of Physics: Conference Series. https://doi.org/10.1088/1742-6596/1287/1/012015

Emda, A. (2017). Laboratorium Sebagai Sarana Pembelajaran Kimia Dalam Meningkatkan Pengetahuan Dan Ketrampilan Kerja Ilmiah. Lantanida Journal, 5(1), 83. https://doi.org/10.22373/lj.v5i1.2061

Forcino, F. L. (2013). The importance of a laboratory section on student learning outcomes in a university introductory earth science course. Journal of Geoscience Education, 61(2), 213-221. https://doi.org/10.5408/12-412.1 
Harahap, N. M. (2019). Pengembangan Alat Peraga Kit Uji Fotosintesis Untuk Meningkatkan Aktivitas Belajar Siswa Kelas Viii-6 Di Mtsn 1 Banda Aceh Tahun Ajaran 2018/2019. Bioilmi: Jurnal Pendidikan, 5(1), 1-9. https://doi.org/10.19109/bioilmi.v5i1.3506

Helfira, R., Ratnawulan, \& Gusnedi. (2019). Analysis of integrated science teacher's book with blood fluids theme using connected to type integrated 21st century learning. Journal of Physics: Conference Series, 1185(1). https://doi.org/10.1088/1742-6596/1185/1/012097

Hofstein, A., \& Lunetta, V. N. (2015). The Role of the Laboratory in Science Teaching: Neglected Aspects of Research. 52(2), 201-217.

Jumadin, L., Hidayat, A., \& Sutopo. (2017). Perlunya Pembelajaran Modelling Instruction pada Materi Gelombang. Jurnal Pendidikan : Teori, Penelitian, Dan Pengembangan, 2(3), 325-330.

Leite, L., \& Dourado, L. (2013). Laboratory Activities, Science Education and Problem-solving Skills. Procedia - Social and Behavioral Sciences, 106, 1677-1686. https://doi.org/10.1016/j.sbspro.2013.12.190

Mahnun, N. (2012). Media Pembelajaran (Kajian terhadap Langkah-langkah Pemilihan Media dan Implementasinya dalam Pembelajaran). Pemikiran Islam, 37(1), 27-35.

Meliarti, D., Djudin, T., \& S, H. T. M. (2015). MENINGKATKAN HASIL BELAJAR SISWA PADA MATERI FISIKA MELALUI PEMBELAJARAN KONTEKSTUAN BERBANTUAN ANIMASI DI SMP. Program Studi Pendidikan Fisika FKIP Untan Pontianak, 4(1), 1-8. Retrieved from http://www.ncbi.nlm.nih.gov/pubmed/17289255\%0Ahttp://dx.doi.org/10.1016/j.jclepro.2011.10.0 08\%0Ahttp://www.uwaba.or.tz/National_Road_Safety_Policy_September_2009.pdf\%0Ahttp://dx.doi .org/10.1016/j.resconrec.2011.03.010\%0Ahttp://dx.doi.org/10.1016/j.pecs.20

Nurrita, T. (2018). Pengembangan Media Pembelajaran Untuk Meningkatkan Hasil Belajar Siswa. Misykat, 3(1), 171-187. Retrieved from https://media.neliti.com/media/publications/271164pengembangan-media-pembelajaran-untuk-me-b2104bd7.pdf

Nurseto, T. (2012). Membuat Media Pembelajaran yang Menarik. Jurnal Ekonomi Dan Pendidikan, 8(1), 1935. https://doi.org/10.21831/jep.v8i1.706

Panjaitan, R. L., Sujana, A., \& Jayadinata, A. K. (2019). Plan your own science experiment: Elaborating students' creativity and problems in science laboratory activity. Journal of Physics: Conference Series, 1318(1). https://doi.org/10.1088/1742-6596/1318/1/012057

Polya, G. (1945). How to Solve It. The Mathematical Gazette, Vol. 30, p. 181. https://doi.org/10.2307/3609122

Prasetyowati, R. (2014). Pembelajaran IPA SMP Menurut Kurikulum 2013. Makalah PPM.

Putri, D. H., Risdianto, E., \& Sutarno, S. (2017). Pre-Service Physics Teachers' Perception toward Hands-on Lab Activity and 21st Century Skills. Journal of Physics: Conference Series, 895(1). https://doi.org/10.1088/1742-6596/895/1/012015

Putri, Desy Hanisa, \& Risdianto, E. (2014). Fisika SMA Di Wilayah Miskin Propinsi Bengkulu. 12(1), 1-6.

Rusdianawati, D., \& Sukarmin. (2017). Pengembangan kit praktikum sebagai media pembelajaran untuk melatihkan keterampilan proses sains berbasis inkuiri pada materi kesetimbangan kimia kelas

Abdullah, M., Mohamed, N., \& Ismail, Z. H. (2009). The effect of an individualized laboratory approach through microscale chemistry experimentation on students ' understanding of chemistry concepts , motivation and attitudes. 53-61. https://doi.org/10.1039/b901461f

Al-khatib, B. A. (2012). The Effect of Using Brainstorming Strategy in Developing Creative Problem Solving Skills among Female Students in Princess Alia University College Department of Psychology and Special Education. American International Journal of Contemporary Research, 2(10), 29-38.

Almeida, M. J. de, Martins, D. R., Sá, M. V, Pires, A. J., \& Tremoço, J. J. (2019). Student Centered Teaching Activities in Secondary Schools and Misconceptions Evolution: Basic Mechanics. Journal of Physics: Conference Series. https://doi.org/10.1088/1742-6596/1287/1/012015

Emda, A. (2017). Laboratorium Sebagai Sarana Pembelajaran Kimia Dalam Meningkatkan Pengetahuan Dan Ketrampilan Kerja Ilmiah. Lantanida Journal, 5(1), 83. https://doi.org/10.22373/lj.v5i1.2061

Forcino, F. L. (2013). The importance of a laboratory section on student learning outcomes in a university introductory earth science course. Journal of Geoscience Education, 61(2), 213-221. https://doi.org/10.5408/12-412.1 
Harahap, N. M. (2019). Pengembangan Alat Peraga Kit Uji Fotosintesis Untuk Meningkatkan Aktivitas Belajar Siswa Kelas Viii-6 Di Mtsn 1 Banda Aceh Tahun Ajaran 2018/2019. Bioilmi: Jurnal Pendidikan, 5(1), 1-9. https://doi.org/10.19109/bioilmi.v5i1.3506

Helfira, R., Ratnawulan, \& Gusnedi. (2019). Analysis of integrated science teacher's book with blood fluids theme using connected to type integrated 21st century learning. Journal of Physics: Conference Series, 1185(1). https://doi.org/10.1088/1742-6596/1185/1/012097

Hofstein, A., \& Lunetta, V. N. (2015). The Role of the Laboratory in Science Teaching : Neglected Aspects of Research. 52(2), 201-217.

Jumadin, L., Hidayat, A., \& Sutopo. (2017). Perlunya Pembelajaran Modelling Instruction pada Materi Gelombang. Jurnal Pendidikan : Teori, Penelitian, Dan Pengembangan, 2(3), 325-330.

Leite, L., \& Dourado, L. (2013). Laboratory Activities, Science Education and Problem-solving Skills. Procedia - Social and Behavioral Sciences, 106, 1677-1686. https://doi.org/10.1016/j.sbspro.2013.12.190

Mahnun, N. (2012). Media Pembelajaran (Kajian terhadap Langkah-langkah Pemilihan Media dan Implementasinya dalam Pembelajaran). Pemikiran Islam, 37(1), 27-35.

Meliarti, D., Djudin, T., \& S, H. T. M. (2015). Meningkatkan hasil belajar siswa pada materi fisika melalui pembelajaran kontekstuan berbantuan animasi di SMP. Program Studi Pendidikan Fisika FKIP Untan Pontianak, 4(1), 1-8. Retrieved from http://dx.doi.org/10.1016/j.jclepro.2011.10.008

Nurrita, T. (2018). Pengembangan Media Pembelajaran Untuk Meningkatkan Hasil Belajar Siswa. Misykat, 3(1), 171-187. Retrieved from https://media.neliti.com/media/publications/271164pengembangan-media-pembelajaran-untuk-me-b2104bd7.pdf

Nurseto, T. (2012). Membuat Media Pembelajaran yang Menarik. Jurnal Ekonomi Dan Pendidikan, 8(1), 1935. https://doi.org/10.21831/jep.v8i1.706

Panjaitan, R. L., Sujana, A., \& Jayadinata, A. K. (2019). Plan your own science experiment: Elaborating students' creativity and problems in science laboratory activity. Journal of Physics: Conference Series, 1318(1). https://doi.org/10.1088/1742-6596/1318/1/012057

Polya, G. (1945). How to Solve It. The Mathematical Gazette, Vol. 30, p. 181. https://doi.org/10.2307/3609122

Prasetyowati, R. (2014). Pembelajaran IPA SMP Menurut Kurikulum 2013. Makalah PPM.

Putri, D. H., Risdianto, E., \& Sutarno, S. (2017). Pre-Service Physics Teachers' Perception toward Hands-on Lab Activity and 21st Century Skills. Journal of Physics: Conference Series, 895(1). https://doi.org/10.1088/1742-6596/895/1/012015

Putri, Desy Hanisa, \& Risdianto, E. (2014). Fisika SMA Di Wilayah Miskin Propinsi Bengkulu. 12(1), 1-6.

Rusdianawati, D., \& Sukarmin. (2017). Pengembangan kit praktikum sebagai media pembelajaran untuk melatihkan keterampilan proses sains berbasis inkuiri pada materi kesetimbangan kimia kelas XI. 6(2), 308-314.

Usrotin, D., Wiyanto, \& Nugroho, S. E. (2013). Penerapan pembelajaran melalui kegiatan laboratorium inkuiri terbimbing untuk meningkatkan kemampuan pemecahan masalah, berkomunikasi, dan bekerjasama. Unnes Physic Education Journal, 2(3).

Widiyatmoko, A., \& Shimizu, K. (2018). An overview of conceptual understanding in science education curriculum in Indonesia. Journal of Physics: Conference Series, 983(1). https://doi.org/10.1088/1742-6596/983/1/012044 